gold electrodeposits are wetted quite well by the tinlead-indium-zinc solder. Similar results were also found for the other solders. The observation that pure gold deposits are wetted best, which has been reported before $(4,9)$, was again confirmed.

\section{References}

1 A. Keil, Metalloberfläche, 1957, 11, (10), 334

2 J. Sagoschen, Galvanotechnik Oberflächenschutz, 1959, $\mathbf{2}, 59$

3 J. P. Fabish, Welding $\mathcal{F}$., 1964, 43, (July supp.), $400 \mathrm{~S}$

4 D. G. Foulke, Prot. Corros. Metal Finish., Proc. Int. Conf. "Surface 66". Basle, 1966, 103

5 R. G. Baker and T. A. Palumbo, Plating, 1971, 58, (8), 791

6 F. C. Disque, Letter to R. R. Crockett, The Bendix Corp., December 5th, 1961

7 C. L. Barber, Laboratory Bulletin, Kester Solder Co., January 25 th, 1963
8 J. D. Keller in: Papers on Soldering, 1962, ASTM Spec. Tech. Publ. No. 319, 3

9 W. B. Harding and H. B. Pressly, Techn. Proc. 50th Ann. Conv. Am. Electroplaters' Soc., 1963, 90

10 U. Harmsen and C. L. Meyer, Z. Metallkunde, 1965, 56, (4), 234

11 C. J. Thwaites, Int. Met. Revs., 1972, 17, 149

12 F. G. Foster in: Papers on Soldering, 1962, ASTM Spec. Tech. Publ., No. 319, 13

$13 \mathrm{~J}$. D. Braun and T. B. Rhinehammer, Trans. ASM, $1963, \mathbf{5 6},(4), 870$

14 H. H. Manko, "Solders and Soldering", McGraw-Hill, New York, 1964

15 P. A. Ainsworth, Gold Bull., 1971, 4, (3), 47

16 M. T. Ludwick, "Indium", Indium Corp. of America, New York, 1950

17 H. Heinzel, Festschrift "50 Jahre Doduco", Pforzheim, 1972

18 U.S. Patent, 3,226,226

19 E. E. Schumacher, G. M. Bouton and G. S. Phipps, Mater. Methods, 1945, 22, (5), 1407

\title{
Wear Properties and Structure of Gold Alloy Deposits
}

In applications of gold plating to sliding contacts high wear resistance of the deposit is an essential requirement. This property is clearly influenced by the surface condition and the mechanical properties of the coating, but hitherto little attention has been directed to the relationship between wear properties and the structure of deposits, and for this reason a paper recently published by Samuel Steinemann of the University of Lausanne and W. Flühmann and W. Saxer of W. Flühmann, Zürich, (l) is of particular interest. This is concerned specifically with a ternary gold alloy electrodeposit of nominal composition 75 per cent gold -22 per cent copper -3 per cent cadmium which is produced under the trade name GALVATRONIC by the Flühmann company, and for which much information is already available concerning its properties and wear performance. In the present paper it is shown how the high strength and low wear of the coating can be explained in terms of the structural features revealed by the $\mathrm{X}$-ray studies.

The authors begin by briefly reviewing modern ideas concerning the nature of the wear process, and an analysis is then made of the wear profiles and other data obtained in the earlier work. The results are expressed in terms of the "representative wear number", $Z$, a dimensionless quantity proposed by Holm as a numerical description of wear, and having a clear physical significance as an indication of the approximate number of atomic layers corresponding to the smearedout wear volume. In the present case the wear number for $10^{6}$ revolutions of the slip ring was in the order of $10^{-2}$ for the unlubricated gold coating, which compares with that typical of a lubricated bearing. With the above significance, this result indicates that one atomic layer would be removed in 100 revolutions if wear remained proportional to sliding distance throughout; however, taking into account the observed increase in wear with sliding distance, the authors conclude that the actual number of revolutions corresponding to the removal of one atom layer is $10^{4}$ to $10^{5}$. $\mathrm{Up}$ to this stage the electrodeposit remains practically free from wear (with brush loading of $140 \mathrm{~g}$ ), after which accelerated abrasion begins, with visible roughening of the surface.
$\mathrm{X}$-ray structural determinations were made on 20 micron deposits on a base of a 75 per cent gold-copper alloy. The results show a very pronounced fibrous orientation of the coating, with crystallites in over 90 per cent of the volume being oriented with octahedral faces lying parallel to the surface. The deposit is completely single-phase, homogeneous and disordered, in contrast to other alloy deposits where separation of copper-rich regions or of less noble compounds with other alloying components is observed.

Fourier analysis of diffraction line profiles permits the determination of the exact centre of gravity of the line, from which can be derived the exact lattice parameter, mean lattice strains, and density of twinning or stacking faults. The results indicate extraordinarily small apparent average grain sizes of 25 to $30 \AA$, with a high density of lattice defects. In discussing the wear properties in relation to structure, the authors refer to hardness and strain measurements made by Gane (2) in the electron microscope which showed that if the indentor were covered by the contaminant film normally present under these conditions, hardness reached the so-called theoretical value, but otherwise narrowly localised stresses in the contact points produced massive plastic slip at reduced force. This latter process, which could lead to deformation and fracture in small contact areas, is apparently absent in the case of the electrodeposit under investigation, because, owing to the very fine grain size, the electrodeposit metal is hard and strong for any dimension of contact, even the submicroscopic. This, according to the authors, is the true explanation of the high wear resistance.

The authors further suggest that the process of electrodeposition offers a subtle "tool" for the production of metals with properties not achieved by conventional metallurgical procedures.

$$
\text { F. H. R. }
$$

\section{References}

1 S. Steinemann, W. Flühmann and W. Saxer, Metalloberfiache, 1975, 29, (4), 154

2 N. Gane, Proc. Roy. Soc. London, [A], 1970, 317, (1530), 367 